\title{
Subsidiariedade: a evolução do princípio constitucional limitador da interferência estatal ${ }^{1}$
}

\author{
Subsidiarity: evolution as a constitutional principle of limiting the state \\ interference
}

\author{
Francisco Carlos Duarte \\ Pontifícia Universidade Católica do Paraná, Curitiba, PR, Brasil \\ Isabella Cristina Costa Nacle \\ Pontifícia Universidade Católica do Paraná, Curitiba, PR, Brasil
}

\begin{abstract}
Resumo: O princípio da subsidiariedade, classicamente compreendido, remete-nos à ideia de ausência de intervenção estatal, em estado liberal. Contudo, alçado referido princípio a nível constitucional, reconhece-se ele como elemento material e necessário ao correto e equilibrado desenvolvimento econômico, verificando-se a possibilidade da comunicação entre binômio público x privado, sem que ambos entrem em conflito. No presente trabalho encontra-se a análise do princípio da subsidiariedade como meio necessário à promoção do desenvolvimento sustentável na economia brasileira, sendo promovida e defendida a ideia da criação de um Estado Subsidiário que garante a atividade econômica do ente privado, somente interferindo nas relações sociais quando verificada a necessidade, visando sempre atingir o bem comum.
\end{abstract}

Palavras-chave: Subsidiariedade. Estado. Atividade Econômica. Direito Constitucional Econômico.

${ }^{1}$ Recebido em: 07/03/2014

Revisado em: 02/04/2014

Aprovado em: 06/05/2014
Abstract: The principle of subsidiarity, classically understood, brings us the idea of the absence of state intervention in the liberal state. However, that principle elevation at constitutional level, it is recognized as the same element material and necessary to correct and balanced economic development, verifying the possibility of communication between public $\mathrm{x}$ private binomial, both without conflict. In the present work is the analysis of the principle of subsidiarity as a necessary means to promote sustainable development in the Brazilian economy, being promoted and defended the idea of statehood Subsidiary that guarantees the economic activity of the private entity, only interfering in social relations verified when needed, always aiming to achieve the common good.

Keywords: Subsidiarity. State. Economic Activity. Economic Constitutional Law. 


\section{Introdução}

Conforme nos alerta José Alfredo de Oliveira Baracho (1997, p. 91) "[...] quando se fala no princípio da subsidiariedade, em termos de Direito Constitucional, se pensa no Estado Federal ou nos princípios da Europa Comunitária, expressos recentemente no Tratado da União Européia". Contudo, ao tratar do princípio da subsidiariedade é necessário fazer a conexão necessária e, quiçá, obrigatória ao direito constitucional, rompendo com a limitação etimológica do termo, que reduz seu conteúdo a limitação de competências; ausência de intervenção ou ainda interferência residual.

Referido princípio guarda, em sua essência, múltiplas facetas que não podem e não conseguem ser encerradas e compreendidas, apenas e tão somente, em sua superfície gramatical. Tratar sobre princípio da subsidiariedade no atual contexto é admitir que tal princípio insere-se e assume caráter para além de mero formalismo, devendo ser compreendido e aplicado como ética política (visão comunitária da sociedade, aplicada atualmente na União Europeia, como elemento base de sustentação de tal sistema); repartição de competências (conectado ao ideal que a cada nível de poder não se pode atribuir e exercer além de suas competências); e, por fim, como elemento de base de formação do Estado.

Não se pode olvidar que a definição, estudo e compreensão do princípio tem demonstrado crescente evolução, seja em seu aspecto formal, seja material, eis que seu conteúdo e forma de aplicação vêm sofrendo transformações.

$\mathrm{Na}$ atual conjuntura referido princípio assume função primordial, reconhecendo que o Estado rompe a ideia de ser apenas e tão somente o mantenedor da sociedade (sua função resumia-se a ditar direitos e deveres) para transformar-se em Estado mantenedor da ordem econômica (que irá então garantir, por via indireta, os direitos e deveres de seus componentes, porém, antes de tudo, de forma subsidiária, aí porque do princípio, preocupar-se-á com os interesses do próprio ordenamento e não de seus membros). Nesse sentido é que Eros Roberto Grau (2006, p. 19) afirma que o Estado moderno surge com a vocação de atuar no campo econômi- 
co; o que é modificado no tempo seria apenas a forma dessa atuação, dirigida inicialmente à constituição e à preservação do modo de produção social capitalista, e posteriormente à substituição e compensação do mercado.

Contudo, antes mesmo de admitir que o princípio da subsidiariedade transformou-se em elemento basilar e estruturante do atual ordenamento econômico, onde o Estado assume o papel de interventor, em caráter excepcional e subsidiário, reservando para si alguns setores que entende serem necessários ao bom desenvolvimento nacional, cabe ser procedida a análise da origem de tal tema, bem como sua evolução. Isso porque, no presente trabalho, busca-se compreender a influência do princípio da subsidiariedade como elemento base da atuação estatal na atividade econômica.

Não obstante, a atividade econômica, neste trabalho, deve ser compreendida em seu sentido estrito, como sendo propriamente a atividade Estatal na economia, prevista no artigo 173 da Constituição de 1988. Isso porque, como bem esclarece Eros Roberto Grau (2006, p. 70-71), a atividade econômica pode ser compreendida em duplo sentido, como prestação de serviços públicos e como, propriamente, atividade econômica em que o Estado passa a explorar determinados setores e assume para si referidas funções, interferindo diretamente no âmbito privado.

\section{Subsidiariedade: de mera utopia a princípio material}

O termo subsidiariedade provém do latim, subsidiarius, que, na linguagem vulgar, significa ajuda, reforço, estímulo, encorajamento, supletivo ou que vem em segundo lugar. (SILVA, de Plácido, 2006, p. 1336). Contudo, conforme já apontado anteriormente, compreender e reduzir referido tema a sua origem gramatical não é suficiente, eis que há vários desmembramentos e aplicabilidades na prática.

Referir-se a princípio é compreender que se está diante de verdadeiras regras jurídicas (enquanto compreendidas como parâmetros, linhas gerais e nortes, não se reduzindo a questão hermenêutica de diferenciação entre princípios ou regras). Isso porque, “[...] os princípios são uma espécie de fronteira do Direito, eles orientam e guiam os que realizam as tare- 
fas de interpretação, pois permitem a compreensão das normas jurídicas" (BARACHO, p. 98). Contudo, não podem os princípios serem valorizados como verdadeiros ou falsos, mas tão somente como vigentes ou não vigentes, sendo verificado na prática que alguns são explícitos (positivados) no texto jurídico ou apenas implícitos (extraídos a partir da leitura conjunta do sistema). (GRAU, 2006, p. 76-79)

Compreender o princípio da subsidiariedade, antes de tudo, é alçá-lo a nível constitucional e considerá-lo como parâmetro maior de atuação estatal, não podendo tratá-lo como mera ideia de aplicação em última instância. Nesse sentido é que o princípio

[...] constitui princípio de atuação do Poder Público, partindo da ideia do respeito à inerente liberdade e iniciativa das pessoas em busca de equilíbrio no relacionamento entre o individuo e os entes governamentais, de forma que estes somente se legitimam na sua atuação para subsidiar os indivíduos nas suas demandas sociais e econômicas que não podem sozinhos alcançar. (SILVA, de Plácido, 2006, p. 995)

Mais ainda: o princípio da subsidiariedade é um princípio de organização social e política, pois é um princípio normativo que indica qual é a função da autoridade, bem como quais são os limites para seu exercício. (SILVA, Daniela, 2006)

Portanto, num primeiro momento compreende-se que o princípio da subsidiariedade parte da consideração do binômio existente entre privado x público, onde de um lado há indivíduos iguais, buscando assegurar seus direitos e liberdades e de outro lado verifica-se o poder estatal, interferindo quando necessário - de forma subsidiária - nas relações sociais. Contudo é necessário ir além e compreender o fundo de tal princípio, isto é, sua essência e intenção.

Nesse sentido é que José Alfredo de Oliveira Baracho (1997, p. 2425) afirma que para compreender o princípio é necessário romper a ideia de reduzi-lo à mera aplicação suplementar e promover ao status de aplicação complementar, sendo que ambos não são de todo dissociáveis. A suplementariedade é tudo aquilo que se acrescenta, que soma, onde de um 
lado verifica-se o poder público e, de outro, os agentes privados, em que ambos se completam na sociedade.

Admitir que o princípio é muito mais que a mera interferência do Estado em última hipótese, instância, é fazer uma (re) leitura do cenário econômico liberal em que o assunto adquire corpo. Isso porque, sabe-se que a origem do referido tema situa-se no choque entre o liberalismo e o socialismo, na dicotomia existente entre as liberdades individuais e a garantia do bem comum.

É nesse panorama então que não se pode deixar de mencionar a Encíclica Rerum Novarum, de 1981, escrita no pontificado Papa Leão XIII, que se renova em 2009 através da Encíclica Caritas in Veritate e anuncia que

[...] o princípio da subsidiariedade há de ser mantido estritamente ligado com o princípio de solidariedade e vice-versa, porque, se a subsidiariedade sem a solidariedade decai no particularismo social, a solidariedade sem a subsidiariedade decai assistencialismo que humilha o sujeito necessitado.

Ainda, acerca da Encíclica Rerum Novarum é necessário esclarecer que nela o princípio da subsidiariedade não vem expresso formalmente, verificando alguns sinais e contornos de seu conteúdo, sendo apenas e tão somente anunciada de forma expressa, quarenta anos após, em 1931, na Encíclica Quadragesimo Anno, através do Papa Pio XI. Nesse cenário o princípio passa a ser compreendido no seu duplo aspecto de caráter suplementar e complementar como já proposto por José Alfredo de Oliveira Baracho.

Não obstante, em 1961, na Encíclica Mater et Magistra, no pontificado Papa João XXIII, o princípio se repete, sustentando que a presença do Estado na atividade econômica não intenta diminuir a esfera de liberdade dos indivíduos, senão destina-se a garantir a essa esfera a maior amplitude possível, ao tutelar os interesses daqueles que necessitam.

Assim, verifica-se que a subsidiariedade, que antes, de forma muito tímida, não constava nos textos normativos da Igreja, passa a exercer 
papel fundamental no exercício de interferência estatal na vida privada de seus componentes e começa a delinear-se de forma expressa. Nesse sentido é que então, no último quartel do século XX, no direito constitucional aquilo que antes era apenas uma ideia, proposta pela Igreja, passa a exercer a função de princípio e destina-se a redirecionar o papel e função do Estado, sendo o objetivo maior o de igualizar as relações jurídico-econômicas e corrigir as distorções verificadas na formulação das políticas econômicas. (MARQUES, 2012)

O princípio da subsidiariedade, que hoje tem sido amplamente aplicado como forma de justificar a interferência do Estado na atividade econômica, antes de tudo, nasceu num cenário de necessidade em que os sujeitos privados aspiravam pela proteção e garantia do ente maior, sem que tal intervenção implicasse em instituição de um estado que violasse a liberdade de seus agentes. E, não de outra forma que, a Igreja no mesmo caminho e identidade da formação do princípio da subsidiariedade, em sua Encíclica Centesimus Annun, do Papa João Paulo II, reconhece que o

Estado deve concorrer tanto directa como indirectamente. Indirectamente e segundo o princípio de subsidiariedade, criando as condições favoráveis ao livre exercício da actividade económica, que leve a uma oferta abundante de postos de trabalho e de fontes de riqueza. Directamente e segundo o princípio de solidariedade, pondo, em defesa do mais débil, algumas limitações à autonomia das partes, que decidem as condições de trabalho, e assegurando em todo o caso um mínimo de condições de vida ao desempregado.

Portanto, observa-se que o princípio da subsidiariedade assume neste século o papel fundamental de elemento necessário e justificador da interferência do âmbito público sobre o privado, em que o

[...] estado deve respeitar os direitos individuais, pelo reconhecimento de que a iniciativa privada [...] tem primazia sobre a iniciativa estatal; em consonância com esse ideia, o Estado deve abster-se de exercer atividades que o particular tem condições de exercer por sua própria iniciativa e com seus próprios recursos. (GUNTHER, 2011, p. 90) 
E, nesse diapasão, admitindo-se então que o princípio passa a ser o próprio motivo, a razão, de limitação da interferência estatal, que se verifica o nascimento do Estado Subsidiário. Conforme bem aponta Maria Sylvia Zanella Di Pietro (2002), o princípio da subsidiariedade assume a importância fundamental de definir o papel do Estado, sendo que o Estado deve fomentar, coordenar, fiscalizar a iniciativa privada, de tal modo a permitir aos particulares, sempre que possível, o sucesso na condenação de seus empreendimentos.

Portanto, observa-se que a ideia inicial da existência de subsidiariedade como elemento que impede a interferência estatal no âmbito privado, como elemento secundário, pautado nos ideais do liberalismo, acaba sendo (re) visitado no atual cenário da atividade econômica como princípio, explícito, a nível constitucional, onde o Estado assume sua posição de membro necessário, presente, porém não limitador, mas sim coadjuvador para o bom desenvolvimento das atividades econômicas.

E, muito embora referido princípio não conste de forma positivada no texto constitucional, como bem afirma José Alfredo de Oliveira Baracho (1997, p. 30), o princípio de subsidiariedade é uma garantia contra a arbitrariedade, procura inclusive suprimi-la. É necessário que toda autoridade investida de funções deva justificar seus atos.

Assim, pode-se afirmar que muito embora referido princípio não esteja inserido de forma expressa na carta constitucional, o mesmo deve ser compreendido em sua forma ampla (e não restrita, de caráter secundário, como classicamente compreendido) vinculado aos valores maiores, visando, sobretudo, valorizar a dignidade da pessoa humana, antes de tudo, justificando assim a existência de um ente maior - o Estado - que por muitas vezes intervém no âmbito privado, com o fito maior de assegurar a existência de uma sociedade digna e justa.

Verifica-se que o princípio da subsidiariedade assume o caráter de limitação positivo da interferência do Estado na economia, não como fator impeditivo, mas sim como fator necessário à própria natureza da intervenção. 


\section{Desdobramentos e Implicações do Reconhecimento da Sub- sidiariedade como Princípio Constitucional no Ordenamento Econômico}

Alçar a subsidiariedade a nível principiológico constitucional implica em reconhecer sua aplicabilidade imediata no ordenamento jurídico atual como forma de justificar então a presença do Estado nas atividades econômicas. Contudo, antes de tudo, é necessário reconhecer que referido princípio assume dupla função, é bivalente, sendo admitida sua função positiva e negativa na esfera privada dos agentes que compõe a sociedade.

Afirmar que o princípio da subsidiariedade é negativo quer dizer, diretamente, que se reveste de garantia constitucional - não expressa, porém existente - da proteção da não intervenção do ente superior sobre o inferior, limitando, por exemplo, a interferência do poder estatal sobre o municipal em competências políticas (LAZARO, 2001, p. 33). Nesse sentido, é que se compreende a razão pela qual, antes de ocorrer uma intervenção, seja no âmbito legislativo ou executivo, faz-se necessário verificar as necessidades da sociedade, estabelecendo os interesses menores e maiores, visando assegurar então a tomada correta de medidas que assegurem o correto e bom desenvolvimento das necessidades passadas, presentes e futuras, ou seja, atingindo o tão falado e esperado desenvolvimento sustentável.

Nesse mesmo sentido é que José Alfredo de Oliveira Baracho (1997, p. 46-47) afirma que o princípio da subsidiariedade, como fator negativo, visa assegurar os interesses da sociedade, tendo como meta propiciar um clima de liberdade em que os agentes, sejam eles inferiores ou superiores, desenvolvam suas capacidades de forma plena. Ou seja, não se trata de admitir a existência de um estado liberal ou ditatorial, mas sim a existência de um estado interventor equilibrado, que assume suas funções na exata medida em que a sociedade assim necessitar.

De outro modo, faz-se necessário reconhecer que o princípio da subsidiariedade também assume aspecto positivo. Nesse sentido é que se verifica a aplicação de tomada de decisões, de entes superiores com maior 
capacidade e competência, sobrepondo-se ao interesse dos inferiores, visando garantir o atingimento dos fins que se espera.

Ainda, no que diz respeito ao aspecto positivo da aplicação do princípio, conforme bem nos alerta Alicia Chicharro Lazaro (2001, p. 34-35) é preciso ter cuidado para que não se deforme o seu conteúdo, no sentido que somente se pode admitir a aplicação positiva dele quando se assegure e respeite os interesses locais e a intromissão do ente superior, sem qual atitude implique em bloqueio da autonomia dos inferiores.

Portanto, admite-se que referido princípio possuí papel de extrema importância no atual ordenamento jurídico, na exata medida em que irá justificar a interferência ou não do Estado no âmbito privado. Nesse sentido é que não se pode interpretar tal princípio como uma proposta de estado débil e mínimo, que simplesmente extirpa suas funções e deixa ao livre arbítrio dos entes privados gerirem o destino de seus negócios, ao contrário, referido princípio encontra respaldo em si mesmo, representando verdadeira fórmula de equilíbrio na atividade econômica.

E, de encontro ao que foi dito, é que José Alfredo de Oliveira Baracho (1997, p. 48-49) afirma,

[...] o equilíbrio do princípio da subsidiariedade não significa não ser lícito, nem justo, que os homens deixem de fazer por suas próprias forças, transferindo para o Estado aquilo que poderiam fazer. [...] Toda intervenção do Estado deve ajudar supletivamente aos membros do corpo social, sem destruí-los, nem absorvê-los. [...] Antes de deferir ao Estado certas competências, devemos verificar se são capazes de resolvê-las os próprios homens ou as sociedades intermediárias [...] quando alguma tarefa pode ser cumprida pelo homem ou pelos grupos sociais, bem como pelo Estado, deve-se dar preferência aos primeiros.

Assim consegue-se compreender o atual cenário econômico, em que o Estado por vezes mantém-se inerte diante dos agentes privados e por outras vezes acaba por interferir diretamente, modificando a vontade daqueles. Por exemplo, nesse sentido, várias medidas vêm sendo adotadas, como a privatização de empresas estatais; a concessão de serviços 
públicos para delegar as atividades, que seriam competência do Estado, aos particulares; a desregulamentação, pela qual se objetiva estabelecer novo parâmetro entre as liberdades e autoridades; o enxugamento do setor administrativo, com a extinção de vários setores da administração indireta e órgãos públicos, bem como a redução do quadro dos servidores públicos.

Não obstante, a fim de deixar claro e delimitado o conteúdo de aplicação do referido princípio, é importante destacar que, muito embora até o presente momento tenha se referido ao elemento justificador da interferência do Estado na economia, se faz necessário esclarecer que em razão de ser um princípio dinâmico, seu conteúdo é aplicável em vários setores e áreas, não sendo objeto de estudo do presente, razão pela qual não se adentra ao pano de fundo de tais. Nesse sentido, por exemplo, se verifica sua utilização para explicar a existência do federalismo, no qual se reconhece a existência unidades autônomas que detém para si competências exclusivas, como o caso do Brasil; do nascimento da União Europeia, que contém a previsão expressa de tal conteúdo no artigo 2-B do Tratado de Maastrich; bem como no Direito Penal para compreender sua função enquanto última ratio, em que somente se justifica a aplicação de tal direito diante da inexistência e fracasso das demais formas de sanções previstas no ordenamento.

Assim, portanto, na prática revela-se que o princípio da subsidiariedade demonstra-se de forma mais cristalina e imediata em matéria econômica. Isso porque, conforme acima visto, seu conteúdo não se restringe a tal setor, porém em razão de que as relações sociais desenvolvem-se, diariamente, na economia, é que se consegue enxergar referido princípio sendo materializado na prática.

No âmbito constitucional, embora já sabido que referido princípio não se encontra positivado, encontra-se a subsidiariedade como elemento material norteador do atual ordenamento. E, somente se pode fazer tal afirmação no atual contexto da Constituição de 1988, eis que não se pode olvidar que as constituições correspondentes ao período liberal se tratavam de constituições políticas, isto é, constituições que visavam e asse- 
guravam apenas e tão somente funções de repartição de poderes e competências. Nesse sentido é que

[...] apenas neste século XX, com a famosa Constituição alemã de 11 de agosto de 1919, a chamada Constituição de Weimar, é que se estenderam as normas constitucionais aos domínios econômico e social [...]. Desde então, as Constituições ocidentais, ainda que continuem a ser primordialmente políticas, contêm normas sobre a "ordem econômica e social", como se dá, no Brasil, a partir de 1934. (FILHO, 1990, p. 33)

Tal transformação, inclusive da aplicação do princípio da subsidiariedade nas constituições econômicas, decorre diretamente da atuação do Estado nos planos econômicos e sociais. E, da mesma forma que se afirma que o princípio da subsidiariedade não pode implicar em limitação da atuação privada e estatal, é preciso referir-se à constituição econômica, razão pela qual a atuação do Estado na atividade econômica passa a ser regulamentada em capítulo dedicado do texto maior.

Assim, é neste cenário, admitindo-se a transformação da Constituição de 1988 em função política, social e, sobretudo, econômica, é que se verifica a transformação do Estado paternalista para um Estado progressista. Nesse sentido é que Eros Roberto Grau (2006, p. 32-33) destaca que o Estado desenha um modelo econômico de bem-estar, que, acima de tudo e de todos, deve garantir a aplicação do texto constitucional, não permitindo que arbitrariedades sejam cometidas na atual ordem econômica.

Em síntese, somente através do reconhecimento do princípio da subsidiariedade como princípio elevado a nível constitucional, devendo assim ser observada sua aplicação diante das regras e valores máximos contidos na carta maior, é que se conseguirá atingir um correto e equilibrado desenvolvimento nacional sustentável. Isto é, somente através da observância dos valores maiores da dignidade da pessoa humana, da livre iniciativa, do direito ao pleno trabalho, é que o Estado poderá intervir no âmbito privado, visando sempre atingir o interesse maior, qual seja: o bem-estar social. 
De outro modo, tratar o princípio da subsidiariedade, deslocado do texto constitucional, desvinculado do ordenamento e conectado apenas e tão somente no cenário econômico é que se permanece em retrocesso, implementando políticas e tomando decisões que não asseguram as futuras gerações, tampouco as passadas, senão apenas o presente.

Portanto, para que se possa estabelecer um cenário econômico saudável, com a devida participação estatal e da sociedade, necessita-se fazer a (re)leitura do princípio da subsidiariedade como sendo princípio que justifica a intervenção do Estado no âmbito privado, quando a sociedade assim clamar e quando, de fato, necessitar reestabelecer o equilíbrio da ordem econômica, culminando em uma democracia que institucionaliza o Estado Subsidiário.

\section{Conclusão}

A Constituição de 1988, conforme visto anteriormente, assumiu o status de constituição política, social e econômica, pautada nos princípios da dignidade da pessoa humana, visando assegurar e instituir além de padrões de divisão de poder, direitos e garantias individuais. Nesse cenário verifica-se a transformação da relação entre Estado e sociedade, onde as relações econômicas são direcionadas ao desenvolvimento sustentável, muitas vezes tendo o Estado que se abster de interferir na vida do ente privado e muitas outras se fazendo presente, ditando as regras e direções das relações. Nesse norte, afirma-se que

[...] a República brasileira tem como objetivos a construção de uma sociedade livre, justa e solidária e a garantia do desenvolvimento nacional, considerados também como princípios fundamentais do Estado brasileiro, assim como a dignidade da pessoa. Podemos entender que o "dever ser" do Estado brasileiro é o crescimento econômico e social, mas valorizando a pessoa e sua livre iniciativa e, por que não dizer, considerando a pessoa o principal sujeito do desenvolvimento. (CAVALCANTI, 2002, p. 213) 
Assim, como forma de possibilitar o objetivo maior da República Brasileira é que se reconhece a existência do princípio da subsidiariedade como forma de possibilitar a existência de um Estado subsidiário, em que parte-se da colaboração entre o privado e o público, justificando assim a presença ou ausência, de acordo com o caso concreto. Nesse sentido, conforme bem alerta Giorgio Vittadini (2002, p. 3-4)

[...] a subsidiariedade na esfera política implica um Estado descentralizado e a realização de políticas públicas que visem ao fortalecimento da sociedade civil como riqueza humana - capital humano - para o desenvolvimento das comunidades e do Estado.

O princípio da subsidiariedade se estabelece assim como elemento essencial e necessário ao desenvolvimento da atual sociedade brasileira. Contudo, muito embora já seja admitido que referido princípio está inserido, de forma não expressa, porém implícita, na carta constitucional, sabe-se que sua utilização vem sendo adotada apenas e tão somente como forma de justificar a presença do estado no âmbito privado.

Conforme já dito, sim, referido princípio guarda em seu âmago essência múltipla, de caráter multifacetado, podendo ser manejado em diversos ramos, como por exemplo, no direito ambiental; direito do trabalho; direito constitucional; direito penal; onde quer que se deseje justificar a aplicação em caráter secundário. E nesse aspecto que não se pode fechar os olhos à realidade brasileira e reconhecer que, atualmente, referido princípio vem sendo utilizado de forma a justificar o falso comportamento estatal de crescimento sustentável.

É inegável que se passe por uma fase onde se tem anunciado o futuro promissor de crescimento brasileiro, cujo desenvolvimento tem sido justificado e comprovado através de dados estatísticos, como por exemplo, o PIB. Contudo, certo é que números não conseguem expressar, verdadeiramente, a atual situação da economia brasileira, sendo que conforme bem anunciou Amartya Sem (2010, p. 19)

[...] o que as pessoas conseguem realizar é influenciado por oportunidades econômicas, liberdades políticas, poderes sociais e por con- 
dições habilitadoras, como boa saúde, educação básica e incentivo e aperfeiçoamento de iniciativas.

Para tentar solucionar o problema da manipulação da economia, do comportamento do Estado perante os agentes privados, é que o princípio da subsidiariedade, elevado a nível constitucional, surge como elemento material necessário ao desenvolvimento sustentável brasileiro. Somente mediante a intervenção, correta, necessária, legítima e, equilibrada do Estado no setor privado e na economia é que será possível alcançar dados estatísticos que, de fato, exprimam o verdadeiro crescimento anunciado.

Considerar o princípio da subsidiariedade como elemento formal necessário ao correto desenvolvimento do Brasil é reconhecer a capacidade, legitimidade e competência de seus cidadãos, é reconhecer a dignidade da pessoa humana, calcada sempre em valores constitucionais, onde somente se justificará a presença do ente maior, o Estado, diante das verdadeiras necessidades que a sociedade clama. Mais ainda, é dizer que não se pretende retornar a um estado liberal, tampouco um estado opressor, mas sim reconhecer a existência de um estado progressista e subsidiário que em conjunto com seus membros atua e trabalha visando atingir o desenvolvimento.

Não de outra forma que uma das possíveis soluções apresentadas ao país é reconhecer que o homem, enquanto elemento principal do Estado, enquanto o cidadão é o principal protagonista. Nesse contexto então, mediante o reconhecimento do princípio da subsidiariedade como meio material de justificar as necessárias intromissões e omissões do Estado no âmbito privado que devem ser promovidas políticas públicas que estimulem a participação da sociedade em conjunto com o setor público, buscando atingir o equilíbrio tão sonhado.

Alçar o princípio da subsidiariedade a nível constitucional e material é reconhecer um novo olhar sobre a sociedade civil, é reconhecer sua capacidade, enquanto agente transformador, que pode colaborar para seu crescimento. Em síntese, não se pode reduzir a subsidiariedade a mero elemento secundário, senão promovê-la cada vez mais a nível principiológico, que implique no fomento empreendedor, em conjunto com o apa- 
rato Estatal, de forma transparente e conjunta com a sociedade, visando alcançar e dar continuidade ao crescimento sustentável que todos da nação brasileira desejam.

\section{Referências}

BARACHO, José Alfredo de Oliveira. O Princípio de subsidiariedade: conceito e evolução. Rio de Janeiro: Forense, 1997.

BENTO XVI, Papa. Carta Encíclica Caritas in Veritate: do Sumo Pontífice Bento XVI aos bispos, presbíteros e diáconos, às pessoas consagradas, aos fieis leigos e a todos os homens de boa vontade sobre o desenvolvimento humano integral na caridade e na verdade. São Paulo: Paulinas, 2009.

CAVALCANTI, Thais Novaes. O princípio da subsidiariedade e a dignidade da pessoa: bases para um novo federalismo. Disponível em: $<$ www.fsba.edu.br/dialogospossiveis>. Acesso em: 5 nov. 2012.

DI PIETRO, Maria Sylvia Zanella. 500 anos de Direito Administrativo Brasileiro. Revista Eletrônica de Direito do Estado, Salvador, Instituto de Direito Público da Bahia, n. 5, jan.-mar. 2006. Disponível em: $<$ http:// www.direitodoestado.com.br>. Acesso em: 5 nov. 2012.

FILHO, Manoel Gonçalves Ferreira. Direito constitucional econômico. São Paulo: Saraiva, 1990.

GRAU, Eros Roberto. A Ordem econômica na Constituição de 1988. São Paulo: Malheiros, 2006.

GUNHTER, Luiz Eduardo. SANTOS, Willians Franklin Lira dos. A encíclica rerum novarum e o princípio da subsidiariedade. In: GUNTHER, Luiz Eduardo. VILLATORE, Marco Antônio Cesar (Coord.). Rerum novarum: estudos em homenagem aos 120 anos da encíclica papal. (Coord.). Curitiba: Juruá, 2011. 
JOÃO PAUlO II, Papa. Carta Encíclica Centesimus Annun: do Sumo Pontífice João Paulo II, aos veneráveis irmãos no episcopado, ao clero, às famílias religiosas, aos fiéis da igreja católica e a todos os homens de boa vontade no centenário da Rerum Novarum. Disponível em: < http:// www.vatican.va/holy_father/john_paul_ii/encyclicals/documents/hf_jpii_enc_01051991_centesimus-annus_po.html>. Acesso em: 5 nov. 2012.

\section{LAZARO, Alicia Chicharro. El Principio de subsidiariedad en La} Unión Europea. Madrid: Aranzadi, 2001.

MARQUES, Carlos Henrique de Magalhães. A ordem econômica e o princípio da subsidiariedade. Agenda PMRAF, n. 7, jan. de 2011. Disponível em: <http://www.pmradv.com.br/novosite/noticias/Interno. aspx?codigo $=481>$. Acesso em: 5 nov. 2012.

SEN, Amartya. Desenvolvimento como liberdade. São Paulo: Companhia das Letras, 2010. p. 19.

SILVA, Daniela Romanelli da. Princípio da subsidiariedade. In: BARRETO, Vicente de Paulo (Coord.) Dicionário de filosofia do direito. São Leopoldo/Rio de Janeiro: Unisinos/Renovar, 2006.

SILVA, De Plácido e. Vocabulário jurídico. 27. ed. Rio de Janeiro: Forense, 2006.

VITTADINI, Giorgio. Liberi di scegliere. Dal Welfare state alla welfare society. Parma: Etas. 2002, p. 3-4.

Francisco Carlos Duarte é Graduado em Direito pela UFPR (1979); mestre em Direito pela PUCSP (1989); doutor em Ciências Jurídicas e Sociais pela UFSC e pela Universitá di Lecce - Itália, na qual foi orientado por Raffaele de Giorgi e Niklas Luhmann. Em 2002, com bolsa concedida pelo CNPq, realizou pós-doutorado pela Universidade Técnica de Lisboa - Portugal orientado pelo prof. José Maria Carvalho Pereira e pela Universitá di Lecce - Itália, orientado novamente por Raffaele De Giorgi. Em 2006, com bolsa concedida pela CAPES, realizou novo pós-doutorado pela Universidad de Granada - Espanha, sob a 
orientação do Professor José Luis Serrano. Atualmente, é professor titular nos cursos de graduação, pós-graduação, mestrado e doutorado em Direito da PUC/ PR. Participa do conselho editorial da Editora Juruá e da Revista de Processo. Como cientista social, especializou-se em teoria da sociedade. Como teórico do direito, desenvolve investigações nos seguintes campos: epistemologia, filosofia, neoconstitucionalismo, argumentação jurídica, hermenêutica constitucional, sociologia ecônomica e análise econômica do Direito. É membro da ABraSD (Associação Brasileira de Pesquisadores em Sociologia do Direito). Atualmente realiza estágio pós-doutoral na UNISINOS sob a supervisão do Prof. Leonel Severo Rocha, onde leciona como professor convidado para a disciplina Sociologia da Economia e das Organizações. E-mail: franciscocduarte@hotmail.com.

Endereço profissional:Av. Batel, 1732, CEP: 80420-090, Batel, Curitiba, PR.

Isabella Cristina Costa Nacle é mestranda na linha de pesquisa "Estado, Atividade Econômica e Desenvolvimento Sustentável" pela PUC/PR; Especialista em Direito do Trabalho pela IBPEX; Prêmio $2^{\circ}$ Lugar Geral no V Evento de Iniciação Científica pela FACINTER, 2008; Menção Honrosa no VI evento de Iniciação Científica pela FACINTER, 2009; Membro do Grupo de Pesquisa "Direito do Trabalho Comparado" da FACINTER e do Grupo de Pesquisa "Regulação Econômica e Atuação Empresarial" pela PUC/PR; Advogada Trabalhista, inscrita na OAB/PR sob n. 58.266; Professora na Universidade Tuiuti do Paraná, ministrando aulas no curso de Direito, nas seguintes disciplinas: Introdução ao Estudo do Direito, Direito Comercial I, II e III e Hermenêutica Jurídica. Ainda, nos cursos de Marketing e Propaganda a disciplina de Direito do Consumidor e no curso de Ciências Contábeis a disciplina Direito das Sociedades. ProfessoraAdvogada do Núcleo de Prática Jurídica, da Universidade Tuiuti do Paraná, no Juizado Especial Criminal de Curitiba.E-mail: bebel.nacle@gmail.com.

Endereço profissional: Av. Sete de Setembro, CJ1801, 4698, CEP: 80240-000 Batel, Curitiba, PR. 